\title{
Obstetric and neonatal outcome in women with epilepsy
}

\author{
Roopa Malik $^{1 *}$, Viral Kumar ${ }^{2}$, Susheela Chaudhary ${ }^{1}$, Nirmala Duhan ${ }^{1}$
}

${ }^{1}$ Department of Obstetrics and Gynecology, ${ }^{2}$ Department of Medicine, Pandit Bhagwat Dayal Sharma Post Graduate Institute of Medical Sciences, Rohtak, Haryana, India

Received: 15 April 2017

Accepted: 08 May 2017

\author{
*Correspondence: \\ Dr. Roopa Malik, \\ E-mail: drroopa.sangwan@gmail.com
}

Copyright: () the author(s), publisher and licensee Medip Academy. This is an open-access article distributed under the terms of the Creative Commons Attribution Non-Commercial License, which permits unrestricted non-commercial use, distribution, and reproduction in any medium, provided the original work is properly cited.

\begin{abstract}
Background: Epilepsy is the second most common neurological disorder complicating pregnancy next to migraine. Both mother and fetus stay at risk due to epilepsy and side effects of antiepileptic's. This retrospective study was conducted to study fetal and maternal outcome in WWE.

Methods: This study was conducted on 55 patients of epilepsy with pregnancy who attended antenatal clinic of our hospital from January 2016 to December 2016. Data was collected using antenatal registers in outdoor settings and medical case sheets in indoor patients and was analyzed statistically.

Results: There were a total of $55 \mathrm{WWE}$ in one year duration. Incidence of epilepsy being $0.4 \%$ in this study. 11 WWE were not on ante epileptic drug when conceived, while $34 \mathrm{WWE}$ were on ante epileptic drugs when conceived, 8 WWE were newly diagnosed and 2 patients had both psychiatric disorders along with epilepsy. There were 3 IUDs, 4 major congenital malformation and 2 minor malformations. 2 major malformation occurred in patients taking both antipsychotic and ante epileptics since conception.

Conclusions: There were a total of 55 WWE in one year duration. Incidence of epilepsy being $0.4 \%$ in this study. 11 WWE were not on ante epileptic drug when conceived, while 34 WWE were on ante epileptic drugs when conceived, 8 WWE were newly diagnosed and 2 patients had both psychiatric disorders along with epilepsy. There were 3 IUDs, 4 major congenital malformation and 2 minor malformations. 2 major malformation occurred in patients taking both antipsychotic and ante epileptics since conception.
\end{abstract}

Keywords: Ante epileptics, Congenital malformation, Epilepsy, Women with epilepsy

\section{INTRODUCTION}

Epilepsy is the most common chronic neurological disorder complicating pregnancy. Incidence of seizure disorder in women attending antenatal clinic is estimated to be $0.3-0.5 \%$ of all births. WWE pose a challenge to both patient as well as clinician. An effective preconceptional counselling and a good medical care during pregnancy are essential in treatment of women with epilepsy (WWE). Pregnancy can have variable effects on seizure frequency. In European registry $60 \%$ WWE remained seizure free during pregnancy. Women with focal seizure and women on polytherapy have a higher risk of seizures during pregnancy. Exposure to AEDs has been associated with two to three times increased risk of major congenital malformations in the infants exposed in utero as compared to normal population. Effective preconceptional counseling and a good medical care during pregnancy is essential for the treatment of the pregnant women with epilepsy. We report a retrospective study of fetomaternal outcome in pregnancy with epilepsy attending tertiary care hospital. ${ }^{1-4}$ 


\section{METHODS}

This study comprised of fifty-five pregnant WWE who attended the antenatal clinics of our hospital in one year duration. The patients were treated under supervision of neurologist, obstetrician, radiologist and a neonatologist. Data was collected using antenatal registers in outdoor settings and medical case record files in indoor patients. Different maternal and fetal parameters were assessed.

\section{RESULTS}

There were 55 cases of WWE in this study. There were 13,576 live births during this duration, the incidence of epilepsy in pregnancy being $0.405 \%$. Out of the 55 patients, 45 had past history of only epilepsy, 8 cases were newly diagnosed during pregnancy and 2 had both epilepsy and psychiatric disorder.

Table 1: Demographic characteristics of WWE.

\begin{tabular}{|lll|}
\hline $\begin{array}{l}\text { Demographic } \\
\text { characteristic } \\
\text { Maternal age }\end{array}$ & $\begin{array}{l}\text { No. of patients } \\
(\mathbf{n = 5 5})\end{array}$ & Percentage \\
\hline$<21$ years & 5 & 9.09 \\
\hline $21-25$ & 32 & 58.18 \\
\hline $26-30$ & 13 & 23.63 \\
\hline $31-35$ & 5 & 9.09 \\
\hline$>35$ & 0 & 0 \\
\hline Parity & & \\
\hline P0 & 30 & 54.54 \\
\hline P1 & 20 & 36.36 \\
\hline P2 & 4 & 7.27 \\
\hline P3 & 1 & 1.81 \\
\hline Residence & & \\
\hline Rural & 45 & 81.81 \\
\hline Urban & 10 & 18.18 \\
\hline
\end{tabular}

Table 1 shows the demographic characteristics of WWE, the age distribution, parity status and residence. Table 2 shows the labour characteristics of WWE. 34 patients were taking antiepileptic since conception and of these 32 were well controlled with same dose throughout the pregnancy. Antiepileptic were started during ANC period in 8 patients, 3 in second and 5 in third trimester (newly diagnosed cases). Seizures despite regular antiepileptic treatment for last several years occurred in only 2 patients and required dose escalation of same antiepileptic. There was no case of status epilepticus and no case of maternal mortality in present study.

There were no cases of abortion in this study while 11 WWE had history of abortion, out of these 2 had previous 3 abortions, 1 had previous 2 abortion and 8 had previous one abortion. None of WWE in this study developed any obstetric complication like PIH, gestational diabetes and antepartum haemorrhage. Out of the total 55 patients, live born infants were delivered in 52. Three fetuses were term intrauterine death (IUD). Out of 55 live born infant's major congenital defects were observed in four babies and minor anomalies in two babies.

Table 2: Labour characteristic of WWE.

\begin{tabular}{|lll|}
\hline Parameter & No. & Percentage \\
\hline Mode of delivery & & \\
\hline Vaginal & 39 & 70.90 \\
\hline Cesarean & 16 & 29.09 \\
\hline Labour onset & & \\
\hline Spontaneous & 46 & 83.63 \\
\hline IOL & 09 & 16.36 \\
\hline Misoprostol & 07 & \\
\hline Cerviprime gel & 02 & \\
\hline
\end{tabular}

Table 3 shows the antiepileptic drug used and the malformations observed in the infants. Major malformations, two hydrocephalous both in patients taking Olanzapine and Levetiracetam, one case of diaphragmatic hernia in Levetiracetam and one case of spina bifida in patient taking Phenobarbitone. Two cases of club foot were seen in patients taking Levetiracetam.

Table 3: AED used by WWE.

\begin{tabular}{|lll|}
\hline Name of AED & No. & $\begin{array}{l}\text { Congenital } \\
\text { malformation }\end{array}$ \\
\hline No treatment & 11 & - \\
\hline Levetricetam & 14 & $2 \mathrm{~m}, 1 \mathrm{M}$ \\
\hline Phenytoin & 11 & - \\
\hline Carbamazepin & 3 & - \\
\hline Oxcarbamazepin & 3 & - \\
\hline Phenobarbitone & 3 & $1 \mathrm{M}$ \\
\hline Sodium valproate & 3 & - \\
\hline $\begin{array}{l}\text { Sodium valproate+ } \\
\text { clobazam }\end{array}$ & 1 & - \\
\hline Carbamazepin+clobazam & 1 & - \\
\hline Levetricetam+olanzapine & 2 & $2 \mathrm{M}$ \\
\hline Carbamazepin+levetricetam & 1 & - \\
\hline $\begin{array}{l}\text { Oxcarbamazepin+ } \\
\text { levetricetam }\end{array}$ & 2 & - \\
\hline Lamotrigine+levetricetam & 1 & - \\
\hline
\end{tabular}

Table 4 shows neonatal outcome in this study. There were three intrauterine fetal death and 52 live births. Low birth weight was seen in $17(30.90 \%)$ new borns.

\begin{tabular}{|lll|}
\hline Neonatal outcome & No. & Percentage \\
\hline Live births & 52 & 94.54 \\
\hline IUD & 3 & 5.45 \\
\hline Birth weight & & \\
\hline$<2 \mathrm{~kg}$ & 2 & 3.63 \\
\hline $2-2.5 \mathrm{~kg}$ & 15 & 27.27 \\
\hline $2.5-3 \mathrm{~kg}$ & 22 & 40 \\
\hline $3-3.5 \mathrm{~kg}$ & 11 & 20 \\
\hline$>3.5 \mathrm{~kg}$ & 5 & 9.09 \\
\hline APGAR at $1 \mathrm{~min}$ & $7.28 \pm 0.89$ & \\
\hline APGAR at $5 \mathrm{~min}$ & $9.29 \pm 0.75$ \\
\hline
\end{tabular}




\section{DISCUSSION}

Pregnancies in WWE are a challenge to both patient as well as clinician in the way that exposure to AED and burden of seizures are responsible for poorer fetal outcome. Therefore, a careful balance has to be made between dose and number of AEDs and burden of seizures for the best possible fetomaternal outcome in pregnancy. Preferably, WWE should be on the least possible dosage and monotherapy of AEDs at the time of conception. ${ }^{5}$

Pregnancy can have a variable effect on seizure frequency. Seizures may decrease or remain unchanged during pregnancy. WWE on polytherapy and those with focal epilepsy are the ones who have highest risk of seizure aggravation during pregnancy. The risk is highest during labour. In our study only 2 patients required dose escalation for control of seizures, $34 \mathrm{WWE}$ who were on AEDs remained seizure free without need for adjustment of AED dosage and 11 WWE who were not on AEDs remained seizure free during pregnancy also. Therefore, in this study $81.8 \%$ remained seizure free during pregnancy. While in European registry 60\% WWE remained seizure free during pregnancy. ${ }^{2,6,7}$

There was no case of abortion in present study while 11 patients had history of abortion the reason may the period of gestation patients were included in the study therefore epilepsy registries may be better way to assess complete antenatal outcome in WWE. In present study, the rate of cesarean section was $29.09 \%$ and induction of labour was done in $16.36 \%$ patients. This is similar to other studies which have reported rate of cesarean section close to $30 \%$. Tomas SV et al have reported no significant difference in rate of cesarean section in WWE as compared to normal healthy population. While in some other studies rate of caesarian section has been seen to be significantly higher as compared to normal population. ${ }^{8-10}$

The most important concerns regarding use of AEDs during pregnancy is potential risk of gross congenital malformation in offspring. There are several possible mechanisms including genetic predisposition, direct effects of seizures, indirect effects of seizures like fall and injuries, poor antenatal care and teratogenic effects of AEDs. Of these, most modifiable factor being exposure to AEDs. AEDs may exert teratogenic effects by several possible mechanisms like inducing folate deficiency which in turn may predispose to neural tube defects, secondly increased oxidative stress related to metabolism of AEDs. Certainly, exposure to polytherapy carries a higher risk of congenital malformation as opposed to monotherapy and Valproate demonstrates serious side effects. In our study, 44 women were on AEDs, of these AEDs were started in $2^{\text {nd }}$ or $3^{\text {rd }}$ trimester in 8 patients. Polytherapy was given in only $6 \mathrm{WWE}$ and 2 patients were on both AEDs and anti-psychotic medication. Major gross congenital malformations were seen in 4 women, of these 2 occurred in women on both AEDs and antipsychotics. So, direct causal relationship cannot be established in these two cases. If we exclude these 2 cases, the incidence of gross congenital malformation in present study comes out to be $5.55 \%$. In WWE who are taking AEDs, the risk of major congenital malformation to the fetus is dependent on the type, number and dose of AED. Among AEDs, lamotrigine, and carbamazepine monotherapy at lower doses have the least risk of major congenital malformation in the offspring. The risk of gross congenital malformation in WWE on AEDs is 5$10 \%$ as compared to $2-4 \%$ in general population. While minor malformation was seen in 2 women $(5.55 \%)$ on AEDs in present study. There were $3(5.45 \%)$ intrauterine fetal death in present study. Folate supplementation was given and level II anomaly scan was done at 12 weeks and 18-20 weeks in all women. All neonates were given vitamin $\mathrm{K} 1 \mathrm{mg}$ intramuscularly at birth. No case of neonatal hemorrhagic disease was seen in present study. Exclusive breastfeeding was advised to all women. ${ }^{6,11-14}$

\section{CONCLUSION}

Most WWE had uneventful pregnancy with delivery. Although the risk of fetal malformation is increased in WWE on AEDs, this can be reduced using the lowest possible dose and the safest AEDs before conception. Careful planning and comprehensive antenatal care with multidisciplinary approach during pregnancy in WWE can have a good maternal as well as fetal outcome.

\section{Funding: No funding sources}

Conflict of interest: None declared

Ethical approval: The study was approved by the Institutional Ethics Committee

\section{REFERENCES}

1. Chattopadhyay N, Mukherjee A, Pati S, Mukhopadhyay P, Gupta D, Ganguly G. Fetomaternal outcome in pregnancy with epilepsy in a tertiary care hospital. J Obstet Gynecol India. 2008;58:406-9.

2. EURAP Study Group. Seizure control and treatment in pregnancy. Observations from the EURAP epilepsy pregnancy registry. Neurol. 2006;66:35460.

3. Thomas SV, Devi CC, Radhakrishnan K, Joshua CS. Seizure pattern during pregnancy and purperium among women with epilepsy. Epilepsia. 2000;41:198-9.

4. Artama M, Ritvanen A, Gissler M, Isojarvi J, Auvinen A. Congenital structural anomalies in offspring of women with epilepsy-a populationbased cohort study in Finland. Int $\mathrm{J}$ Epidemiol. 2006;35:280-7.

5. Royal College of Obstetricians and Gynaecologists. Epilepsy in pregnancy. Green- top guideline No.68. June 2016.

6. Thomas SV. Managing epilepsy in pregnancy. Neurol India. 2011;59:59-65. 
7. Thomas SV, Devi CC, Radhakrishnan K, Joshua CS. Seizure pattern during pregnancy and puerperium among women with epilepsy. Epilepsia. 2000;41:198-9.

8. Saleh AM, Abotalib ZM, Al-Ibrahim AA, Al-Sultan SM. Comparison of maternal and fetal outcomes, in epileptic and non-epileptic women. Saudi Med J. 2008;29:261-6.

9. Thomas SV, Sindhu K, Ajaykumar B, Sulekha Devi PB, Sujamol J. Maternal and obstetric outcome of women with epilepsy. Seizure. 2009;18:163-6.

10. Pilo C, Wide K, Winbladh B. Pregnancy, delivery, and neonatal complications after treatment with antiepileptic drugs. Acta Obstet Gynecol Scand 2006;85:643-6.

11. Tomson T, Battino D, Bonizzoni E, Craig J, Lindhout D, Sabers A, et al. EURAP study group.
Dose-dependent risk of malformations with antiepileptic drugs: an analysis of data from the EURAP epilepsy and pregnancy registry. Lancet Neurol. 2011;10:609-17.

12. Morrel MJ. Epilepsy in women. Am Fam Physician. 2002;66:1489-94.

13. Nathan J. Women with epilepsy. J Obstet Gynecol India. 2004;54:543-53.

14. Morel MJ. Epilepsy and pregnancy: minimizing the risks. Contemp Obstet Gynecol. 2004:49:51-70.

Cite this article as: Malik R, Kumar V, Chaudhary $S$, Duhan N. Obstetric and neonatal outcome in women with epilepsy. Int J Reprod Contracept Obstet Gynecol 2017;6:2593-6. 